\title{
On the Composition of the Lunar Interior
}

\author{
Don L. ANDERSON \\ Seismological Laboratory. Californio Institute of Technology. Pasadena, California 91109
}

\begin{abstract}
There is now abundant geophysical and geochemical evidence suggesting that the moon has a thick plagioclase rich outer shell. This is most easily explained by early and extensive melting of a $\mathrm{CaO}$ and $\mathrm{Al}_{2} \mathrm{O}_{3}$ rich moon followed by fractional crystallization involving plagioclase flotation. Melilite is probably an important constituent of the interior. This model explains the seismic velocities, the mean density, and the moment of inertia of the moon. The moon is $73-88 \%$ high-temperature condensate.
\end{abstract}

In a previous paper [Anderson, 1973b] I concluded that the gross physical properties of the moon such as its mass and moment of inertia did not place significant constraints on the major element abundances of the deep lunar interior except that the moon was clearly deficient in iron in relation to cosmic, chondritic, or terrestrial abundances. In particular, this kind of data cannot be used to place upper bounds on the $\mathrm{CaO}$ and $\mathrm{Al}_{2} \mathrm{O}_{3}$ content. However, the surface evidence suggests that the moon is also deficient in elements and compounds more volatile than iron. This led to the suggestion [Anderson, 1972, $1973 a, c, d]$ that the interior of the moon was enriched in $\mathrm{CaO}$ and $\mathrm{Al}_{2} \mathrm{O}_{3}$. This is in direct conflict with the conclusion of Ringwood and Essene [1970] and Ringwood [1970]. In the model of Anderson [1972, 1973a] the moon is refractory rich and is composed predominantly of material less volatile than iron. Such a moon would be enriched in the refractory trace elements by about a factor of 16 relative to chondritic abundances and upon melting or fractional crystallization would yield a plagioclase-pyroxene outer shell of the order of $250-\mathrm{km}$ thickness. A mixture of about $14 \%$ basalt and $86 \%$ anorthosite satisfies the bulk chemistry of this layer and eliminates the Eu anomaly. Melilite, an important component of the interior in this model, can also retain Eu relative to the other REE (rare earth elements). This would reduce the required thickness of a plagioclase rich outer shell. However, these proportions are broadly consistent with the areal extent of the maria and the volumetric relationships implied by elevation differences, offset of center of mass, and the moments of inertia [Wood et al., 1970; Wood, 1973]. The Allende inclusions have many of the properties inferred for the moon, such as depletion of volatiles and appropriate levels of the incompatible trace elements. The inclusions show that compounds in the nebula can be separated on the basis of their volatility.

In most discussions of the composition of the deep lunar interior the assumption is made that the lunar mantle is predominantly olivine and pyroxene. There is a strong terrestrial and meteoritic bias behind these assumptions. The fact that the moon is clearly depleted in iron compared with the terrestrial planets and cosmic abundances suggests that the moon may be unique in other respects. Trace element studies support this suggestion and imply that the source region of lunar igneous rocks is enriched in refractories. Ringwood $[1970$, p. 6467] suggested that major phase changes in the lunar interior are not tolerable and that 'for all practical purposes, this limits the mean $\mathrm{Al}_{2} \mathrm{O}_{3}$ and $\mathrm{CaO}$ contents of the lunar interior to less than $6 \%$ each, and that the Moon, like the earth's mantle, is dominantly composed of iron-magnesium silicates.'

Copyright (c) 1975 by the American Geophysical Union.
Anderson [1973b], however, showed that high $\mathrm{CaO}$ and $\mathrm{Al}_{2} \mathrm{O}_{8}$ peridotites have broader intermediate density fields than the Ringwood-Essene 'lunar pyroxenite' and also that the gabbroeclogite transformation pressure increases with $\mathrm{Al}_{2} \mathrm{O}_{3}$ content. Therefore the moon can have a thick plagioclase rich outer shell [Gast et al., 1970; Gast, 1972; Wood, 1973] and a high CaAl interior [Anderson, 1972, 1973a, c, d]. Minerals likely to be important in the lunar interior, in addition to olivine and pyroxene, are melilite, spinel, Ca-garnet, merwinite, and possibly corundum and perovskite.

The geophysical and geochemical data relevant, or possibly relevant, to the deep interior (density, moment of inertia, seismic, electrical conductivity, heat flow, strength, and trace element distributions) are consistent with the refractory model [Anderson, 1973a, b, c, d; Hanks and Anderson, 1972; Anderson and Hanks, 1972; Anderson and Kovach, 1972]. Further implications of the model that are consistent with more recent studies are the thick low-density outer shell [Wood, 1973] and the high REE content of this shell [Helmke et al., 1972, 1973].

Toksöz et al. [1972, 1973] on the basis of seismic data propose velocities of $7.5-7.7 \mathrm{~km} / \mathrm{s}$ in the lunar mantle down to at least $150 \mathrm{~km}$. These velocities can be compared with the range $7.5-7.6 \mathrm{~km} / \mathrm{s}$ for terrestrial anorthosites with more than 95 vol \% plagioclase [Wang et al., 1973]. The average crustal composition in the refractory model prior to differentiation is $\sim 80 \%$ gabbroic anorthosite and $\sim 20 \% \mathrm{Ca}$ rich pyroxene. This yields a velocity of about $7.7 \mathrm{~km} / \mathrm{s}$. It will increase upon removal of gabbroic anorthosite (the presumed composition of most of the overlying crust) and decrease upon removal of pyroxenes. Considering the relative proportions of plagioclase and pyroxene in the lunar crust inferred from REE, topographic, and orbiter $\mathrm{X}$ ray data, the above is probably a lower bound for the upper mantle velocity in the refractory model.

The high-velocity layer at a depth of $65 \mathrm{~km}$ has been interpreted by Anderson and Kovach [1972] as a high-density refractory layer of limited thickness. Candidate materials include spinel, corundum, kyanite, and $\mathrm{Ca}$ rich garnet, all of which are $\mathrm{CaO}$ and/or $\mathrm{Al}_{2} \mathrm{O}_{3}$ rich. Ferromagnesium silicates such as olivine, pyroxene, and Ca-free garnets do not have the requisite velocities.

The Ringwood-Essene pyroxenite undergoes phase changes between 100 and $200 \mathrm{~km}$ to spinel pyroxenite with density 3.42 $\mathrm{g} / \mathrm{cm}^{3}$ and $V_{P}=8.3-8.45 \mathrm{~km} / \mathrm{s}$ and between 500 and $800 \mathrm{~km}$ to a garnet pyroxenite with $\rho=3.52 \mathrm{~g} / \mathrm{cm}^{3}$ and $V_{P}=8.3-8.6$ $\mathrm{km} / \mathrm{s}$ [Anderson and Kovach, 1972]. This model is therefore not consistent with the seismic data.

There is additional evidence for a thick low-density ( $\sim 2.9$ $\mathrm{g} / \mathrm{cm}^{3}$ ) layer on the moon [Wood, 1973]. This layer, 
presumably gabbroic anorthosite, extends to at least $150 \mathrm{~km}$ on the lunar back side and is probably also thick under the front side highlands. This estimate is a minimum, since it is tied to the seismic crustal thickness under the near side maria. If the $7.7-\mathrm{km} / \mathrm{s}$ layer represents low-density material, then inferred crustal thickness would be greater. Higher-density and higher-velocity layers would be $\mathrm{Ca}-\mathrm{Al}$ rich cumulates, representing the residual phases after basalt or anorthosite removal. The density of this region in the Ringwood model would be $3.27 \mathrm{~g} / \mathrm{cm}^{3}$, much higher than that of Wood's [1973] model.

A thick plagioclase rich crust and a $\mathrm{Ca}-\mathrm{Al}$ rich interior are consistent with the lunar density and $\mathrm{C} / \mathrm{MR}^{2}$. If we adopt 2.9 $\mathrm{g} / \mathrm{cm}^{3}$ for the mean density of the crustal layers, $3.6 \mathrm{~g} / \mathrm{cm}^{3}$ for the 40-km thick subcrustal layer [Toksöz et al., 1973; Anderson and Kovach. 1972], and $3.0 \mathrm{~g} / \mathrm{cm}^{3}$ for the remainder of the moon above $250 \mathrm{~km}$, then the density of the lower mantle required to satisfy the lunar density is $3.5 \mathrm{~g} / \mathrm{cm}^{3}$. This can be compared with the $3.4-\mathrm{g} / \mathrm{cm}^{3}$ density predicted by Anderson [1973a] on the basis of the refractory model, assuming complete separation of the residual crystals (spinel, merwinite, diopside) from the low-melting fraction of the early condensate. The presence of $\mathrm{Ca}$ rich garnet, perovskite, or corundum in the lower lunar mantle would serve to increase the density. The moment of inertia for the model as it stands is 0.391 , in agreement with the new value $0.395 \pm 0.005$ [Bender et al., 1973].

Incompatible trace elements in the Apollo basalts at levels of 30-100 times higher than chondritic abundance levels suggested to Ringwood [1970] that maria were derived by a small degree of partial melting of volumes 30-100 times greater than their own, chondritic abundances in the source region being assumed. In contrast to this assumption Helmke et al. $[1972,1973]$ propose that the common parent material for both the massive lunar anorthosites and the lunar basalts was about 14 times richer in REE than in chondrites. The heat flow data indicate similarly high $\mathrm{U}$ and $\mathrm{Th}$ abundances for the lunar interior [Hanks and Anderson, 1972], and these are also consistent with high $\mathrm{Ca}, \mathrm{Al}, \mathrm{Ba}, \mathrm{Sr}$, and $\mathrm{REE}$ abundances. The early condensates and the Allende inclusions both have the desired properties. The preiron condensates constitute $6 \%$ of the mass of material of solar or chondritic composition and will be enriched by a factor of about 17 in the refractory trace elements; the $\mathrm{CaO}-\mathrm{Al}_{2} \mathrm{O}_{3}$ rich Allende inclusions are enriched by about a factor of 16 [Anderson, 1973a]. Table 1 gives the abundances of several refractory elements in the moon and for comparison, abundances in the $\mathrm{CaO}-\mathrm{Al}_{2} \mathrm{O}_{3}$ rich inclusions in the Allende meteorite and chondritic abundances. Also given

TABLE 1. Abundances of Refractory Elements in the Moon

\begin{tabular}{lccc}
\hline & $\begin{array}{c}\text { Allende } \\
\text { Inclusions }\end{array}$ & Moon $\dagger$ & $\begin{array}{c}\text { Carbonaceous } \\
\text { Chondrites }\end{array}$ \\
\hline $\mathrm{Sm}$ & 2.8 & 2.5 & 0.2 \\
$\mathrm{Eu}$ & 1.3 & 1.0 & 0.07 \\
$\mathrm{Sm} / \mathrm{Eu}$ & 2.2 & 2.5 & 2.9 \\
$\mathrm{Rb} / \mathrm{Sr}$ & 0.02 & $<0.08$ & 0.29 \\
$\mathrm{~K} / \mathrm{Ba}$ & $<9$ & $<8.4$ & 187 \\
$\mathrm{U}$ & 0.12 & 0.09 & 0.01 \\
$\mathrm{~K} / \mathrm{U}$ & $\sim 2 \times 10^{\mathrm{s}}$ & $\sim 2 \times 10^{3}$ & $\sim 3 \times 10^{5}$ \\
\hline
\end{tabular}

* Data are from Gast et al. [1970] and H. Wenke (personal communication, 1973).

$\dagger$ Data are from Helmke et al. [1972], Philpotts et al. [1972], Schonfeld and Meyer [1972], Hanks and Anderson [1972], and Anderson [1973a]. are several volatile/refractory pairs that remain relatively constant during differentiation processes. The moon is enriched by an order of magnitude in the refractories relative to carbonaceous chondrites and depleted by several orders of magnitude in the volatile/refractory ratios. On the other hand, the Allende inclusions are within $30 \%$ of the inferred lunar abundances for the refractories and satisfy the volatile/refractory ratios. The $\mathrm{Sm}, \mathrm{Eu}$, and $\mathrm{U}$ abundances can be modeled as a two-component system containing $73-88 \%$ hightemperature condensates and $12-27 \%$ carbonaceous chondrites. Gast [1972] points out that the Ringwood-Essene hypothesis conflicts with the $\mathrm{Sr}$ and Eu anomalies, which indicate the importance of plagioclase at some time in the history of the Apollo 11 basalts. He also suggests that melilite will behave like plagioclase in its ability to retain $\mathrm{Eu}$ and $\mathrm{Sr}$. $\mathrm{He}$ did not pursue this point, but the Eu and $\mathrm{Sr}$ deficiencies in the lunar maria basalts are obviously consistent with the involvement of either plagioclase or melilite or both in the thermal evolution of the moon. In the present model, plagioclase is an important constituent of the outer shell, and melilite is important in the interior.

The refractory model explains the major and minor element distribution in the lunar crust, the great thickness of the lowdensity crust, the heat flow, the seismic and density data, and the mean value of the moment of inertia coefficient. It also explains in a straightforward way the Eu anomaly, either through plagioclase or melilite removal.

The presence of a very thick plagioclase rich layer on the moon suggests that the lunar interior was extensively and efficiently differentiated. This differentiation apparently occurred very early in the history of the moon and may have been contemporaneous with accretion. Rapid accretion combined with the initially high temperatures of the condensation model [Hanks and Anderson, 1972] suggests that the moon was extensively molten early in its history [Anderson and Hanks, 1972]. I proposed earlier [Anderson, 1973a] that the present internal structure resulted from fractional crystallization involving most if not all of the moon. A similar suggestion was made by Wood et al. [1970]. The trace element abundances in the lunar crust [Anderson, 1973a] are consistent with the fractional crystallization calculations of Gast et al. [1970], although they did not consider melilite as a possible residual phase.

Acknowledgments. This note is a combination and condensation of replies written in response to extensive comments by $A$. E. Ringwood on 'Removal of a constraint on the composition of the lunar interior.' I would like to thank Ringwood for this opportunity to elaborate further on the present constraints regarding the interior of the moon. Although he withdrew his objections, he does not necessarily subscribe to all the views in this paper. This work was supported by NASA grant NGL 05-002-069. Contribution 2520 of the Division of Geological Sciences, California Institute of Technology, Pasadena, California 91109.

\section{REFERENCES}

Anderson, D. L., The origin of the moon, Nature, 239, 263-265, 1972.

Anderson, D. L., The composition and origin of the moon, Earth Planet. Sci. Lett., 18, 301-316, 1973a.

Anderson, D. L., Removal of a constraint on the composition of the lunar interior, J. Geophys. Res., 78, 3222-3225, 1973 b.

Anderson, D. L., The moon as a high temperature condensate, Moon. 8, 33-57, 1973c.

Anderson, D. L., The formation of the moon, in Lunar Science IV, edited by J. W. Chamberlain and C. Watkins, Lunar Science Institute, Houston, Tex., 1973d.

Anderson, D. L., and T. C. Hanks, Is the moon hot or cold?, Science. '178, 1245-1249, 1972. 
Anderson, D. L., and R. L. Kovach, The lunar interior, Phys. Earth Planet. Interiors, 6, 116-122, 1972.

Bender, P., D. Currie, R. Dicke, D. Eckhardt, J. Faller, W. Kaula, J. Mulholland, H. Plotkin, S. Poultney, E. Silverberg, D. Wilkinson, J. Wilkins, and C. Alley, The lunar laser ranging experiment, Science. 182, 229-238, 1973.

Gast, P. W., The chemical composition and structure of the moon, Moon, 5, 121-148, 1972.

Gast, P. W., N. J. Hubbard, and H. Wiesmann, Chemical composition and petrogenesis of basalts from Tranquillity Base, Proc. Apollo II Lunar Sci. Conf., 2, 1143-1163, 1970.

Hanks, T. C., and D. L. Anderson, Origin, evolution and present thermal state of the moon, Phys. Earth Planet. Interiors, 5, 409-425, 1972.

Helmke, P. A., L. A. Haskin, R. L. Korotev, and K. E. Ziege, Rare earths and other trace elements in Apollo 14 samples, Proc. Lunar Sci. Conf. 3rd, 2, 1-1275, 1972.

Helmke, P. A., D. P. Blanchard, L. A. Haskin, K. M. Telander, C. K. Weiss, and J. W. Jacobs, Major and trace elements in crystalline rocks from Apollo 15, in Lunar Science $I V$, edited by J. W. Chamberlain and C. Watkins, Lunar Science Institute, Houston, Tex., 1973.

Philpotts, J. A., C. C. Schnetzler, D. F. Nava, M. L. Bottino, P. D. Fullagar, H. H. Thomas, S. Schuhmann, and C. W. Kouns, Apollo 14: Some geochemical aspects, Proc. Lunar Sci. Conf. 3rd, 2, I1293, 1972.

Ringwood, A. E., Petrogenesis of Apollo 11 basalts and implications for lunar origin, J. Geophys. Res., 75, 6453-6479, 1970.
Ringwood, A. E., and E. Essene, Petrogenesis of Apollo 11 basalts, Internal constitution and origin of the moon, Proc. Apollo II Lunar Sci. Conf., I, 769-799, 1970.

Schonfeld, E., and C. Meyer, Jr., The abundances of components of the lunar soils by a least-squares mixing model and the formation age of KREEP, Proc. Lunar Sci. Conf. 3rd, 2, 1-1397, 1972.

Toksōz, M. N., F. Press, K. Anderson, A. Dainty, G. Latham, M. Ewing, J. Dorman, D. Lammlein, Y. Nakamura, G. Sutton, and F. Uennebier, Velocity structure and properties of the lunar crust, Moon, 4. 490-504, 1972.

Toksoz, M. N., F. Press, A. Dainty, S. C. Soloman, and K. Anderson, Lunar structure, compositional inferences and thermal history, in Lunar Science IV, edited by J. W. Chamberlain and C. Watkins, pp. 734-736, Lunar Science Institute, Houston, Tex., 1973.

Wang, H.. T. Todd, D. Richter, and G. Simmons, Elastic properties of plagioclase aggregates and seismic velocities in the moon, in Lunar Science IV, edited by J. W. Chamberlain and C. Watkins, Lunar Science Institute, Houston, Tex., 1973.

Wood, J. A., Asymmetry of the moon, in Lunar Science IV, edited by J. W. Chamberlain and C. Watkins, pp. 790-792, Lunar Science Institute, Houston, Tex., 1973.

Wood, J. A., J. S. Dickey, Jr., J. B. Marvin, and B. N. Powell, Lunar anorthosites and a geophysical model of the moon, Proc. Apollo 11 Lunar Sci. Conf., I. 965-988, 1970.

(Received December 10, 1973; revised July 29, 1974; accepted December 2, 1974.) 